\title{
Indirect (hydrogen-driven) electrodeposition of porous silver onto a palladium membrane
}

\author{
Tinakorn Kanyanee ${ }^{1,2,3} \cdot$ Philip J. Fletcher $^{4} \cdot$ Elena Madrid $^{1} \cdot$ Frank Marken $^{1}$
}

Received: 5 March 2020 / Revised: 2 April 2020 / Accepted: 2 April 2020 / Published online: 17 April 2020

(C) The Author(s) 2020

\begin{abstract}
Hydrogen permeation through a pure palladium film ( $25 \mu \mathrm{m}$ thickness, optically dense) is employed to trigger electron transfer (hydrogen-driven) reactions at the external palladium | aqueous electrolyte interface of a two-compartment electrochemical cell. Two systems are investigated to demonstrate feasibility for (i) indirect hydrogen-mediated silver electrodeposition with externally applied potential and (ii) indirect hydrogen-mediated silver electrodeposition driven by external formic acid decomposition. In both cases, porous metal deposits form as observed by optical and electron microscopies. Processes are self-limited as metal deposition blocks the palladium surface and thereby slows down further hydrogen permeation. The proposed methods could be employed for a wider range of metals, and they could provide an alternative (non-electrochemical or indirect) procedure for metal removal or metal recovery processes or for indirect metal sensing.
\end{abstract}

Keywords Indirect electrodeposition $\cdot$ Reduction by hydrogen $\cdot$ Palladium membrane $\cdot$ Dendritic silver $\cdot$ Porous silver $\cdot$ Metal recovery

\section{Introduction}

Metal electrodeposition processes are used primarily in metal and metal alloy coating $[1,2]$ and in metal recovery from wastes $[3,4]$. Metal electrodeposition and stripping processes are also an integral part of electroanalytical procedures to determine trace metal in water or in the environment [5]. Electrodeposition is dependent on the applied potential, on the substrate, and on the type of metal that is formed. Electrodeposition is also a key technology in the fabrication of many microelectronic, optoelectronic, and microsystem

Tinakorn Kanyanee

tinakorn.kanyanee@cmu.ac.th

Frank Marken

F.Marken@bath.ac.uk

1 Department of Chemistry, University of Bath, Claverton Down, Bath BA2 7AY, UK

2 Department of Chemistry, Faculty of Science, Chiang Mai University, Chiang Mai 50200, Thailand

3 Center of Excellence in Materials Science and Technology, Chiang Mai University, Chiang Mai 50200, Thailand

4 Materials and Chemical Characterisation Facility (MC2), University of Bath, Claverton Down, Bath BA2 7AY, UK devices [6,7]. Electrodeposition can be cost-effective and useful for conformal coating of complex shapes and objects [8]. An interesting recent development is electrodeposition of metals from non-aqueous or non-traditional solution environments [9]. Electroless plating can be performed by adding chemical-reducing agents directly into the metal ion solution to be deposited, for example, to prepare palladium-metal and alloy films $[10,11]$. Complex geometries can be electrolessly metal-coated [12]. Here, rather than directly adding a reducing agent, hydrogen permeating through a palladium film is used to indirectly drive metal deposition processes.

Palladium can be formed into dense metal membranes with catalytic activity to be used for hydrogen production [13-15] and for hydrogen permeation/purification in membrane reactors [16]. Hydrogen can penetrate through the lattice of the palladium membrane [17] and can thereby be used in hydrogen separation/purification units [18]. There are other types of metal membranes that were studied for $\mathrm{H}_{2}$ separation/ purification applications [19], although palladium offers an excellent choice since it provides (i) good ability to bind hydrogen, (ii) excellent $\mathrm{H}_{2}$ permeability, and (iii) good catalytic surface properties. Additional tolerance to embrittlement due to $\mathrm{H}_{2}$ (caused by an $\alpha-\beta$ phase transition for $\mathrm{PdH}_{x}$ with $x>0.67$ [20-22]) can be achieved, for example, by working with silver-palladium alloys [23]. 
Hydrogen gas has been studied and used previously as a reducing agent, and it can be considered to be a "green" lowwaste reagent [24]. Hydrogen gas as a reductant provides a further benefit as it is removed very easily without the need for further cleaning the product. In theory, hydrogen gas could be applied as a reducing agent for the production of many metals and materials [22]. Processes based on hydrogen permeation through palladium membranes are economically important $[25,26]$. Processes have been proposed for atom-efficient electrosyntheses by allowing processes at anode and cathode to be separated by a palladium membrane to give independent products [27]. Berlinguette and co-workers designed and demonstrated the use of the palladium membrane with hydrogen permeation to extract the $\mathrm{H}_{2}$ gas as a by-product in an anodic electrochemical oxidation of alcohols. The hydrogen is extracted and used for the hydrogenation of unsaturated bonds in organic molecules directly at the palladium surface [28]. It is interesting to ask whether hydrogen permeating through a palladium membrane can be used only in hydrogenation reactions or also in a much broader range of applications including metal reduction and electrodeposition.

A schematic drawing of the two-compartment cell with a palladium membrane separator is shown in Fig. 1a. A metal salt added to the left electrochemical compartment would lead to direct electrodeposition onto the working electrode. However, a metal salt added to the right non-electrochemical compartment would require hydrogen generation in the left compartment, permeation of hydrogen through the palladium film, and reactions of hydrogen in the right compartment to lead to the indirect electrochemical deposition of metals. As a result of these reaction conditions, the growth of metals in the right compartment could be possible in the absence of added electrolyte, but it has to produce porous deposits to sustain the flow of hydrogen as the reducing agent.
In this study, a $25-\mu \mathrm{m}$-thick palladium membrane is used for electrochemical $\mathrm{H}_{2}$ generation in the left compartment (see Fig. 1a). This is coupled to hydrogen permeation through palladium and $\mathrm{H}_{2}$ gas driving the indirect electrodeposition of metals in the right compartment. The palladium membrane is used as an electrode to generate hydrogen gas in the left compartment (the left electrochemistry compartment). After permeation through the Pd membrane, the hydrogen induces a negative potential to cause electrodeposition in the right compartment (right deposition compartment). Silver deposition onto palladium is demonstrated. In addition, the chemical hydrogen generation from the decomposition of formic acid (using Pd as both a catalyst and a membrane) is demonstrated to also allow indirect silver electrodeposition.

\section{Experimental}

\section{Chemical reagents}

Reagents and electrolyte salts were obtained from SigmaAldrich in the highest available purity and used without further purification. A $10 \mathrm{mM} \mathrm{Ag}^{+}$solution was prepared from silver nitrate $\left(99 \%\right.$, Sigma-Aldrich) in aqueous $10 \mathrm{mM} \mathrm{HNO}_{3}$. A $1 \mathrm{mM} \mathrm{AuCl}_{4}{ }^{-}$solution was prepared from potassium tetrachloroaurate(III) $(99.995 \%$, Sigma-Aldrich) and aqueous $10 \mathrm{mM} \mathrm{HCl}$. Demineralized/filtered water was ultrapure of resistivity $18.2 \mathrm{M} \Omega \mathrm{cm}$ (at room temperature) from an ELGA Purelab Classic system.

\section{Instrumentation}

A computer-controlled potentiostat (CompactStat, Ivium, The Netherlands) was used throughout for the experiments.

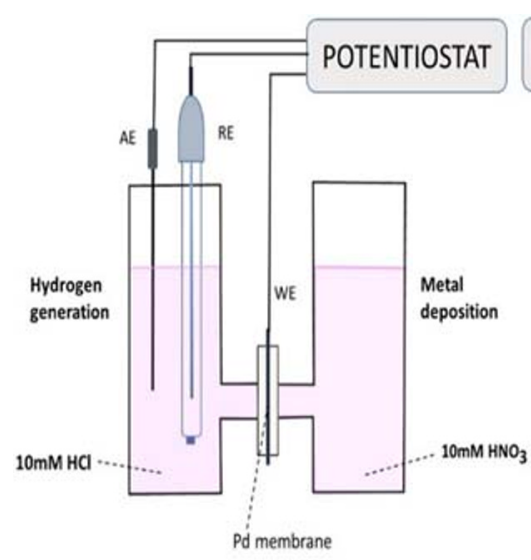

a

Fig. 1 Schematic description of (a) the two-compartment electrochemical cell for electrochemical generation of hydrogen on the left-hand side and indirect electrochemical metal deposition on the right-hand side. In (b), the same cell configuration is shown with additional potential

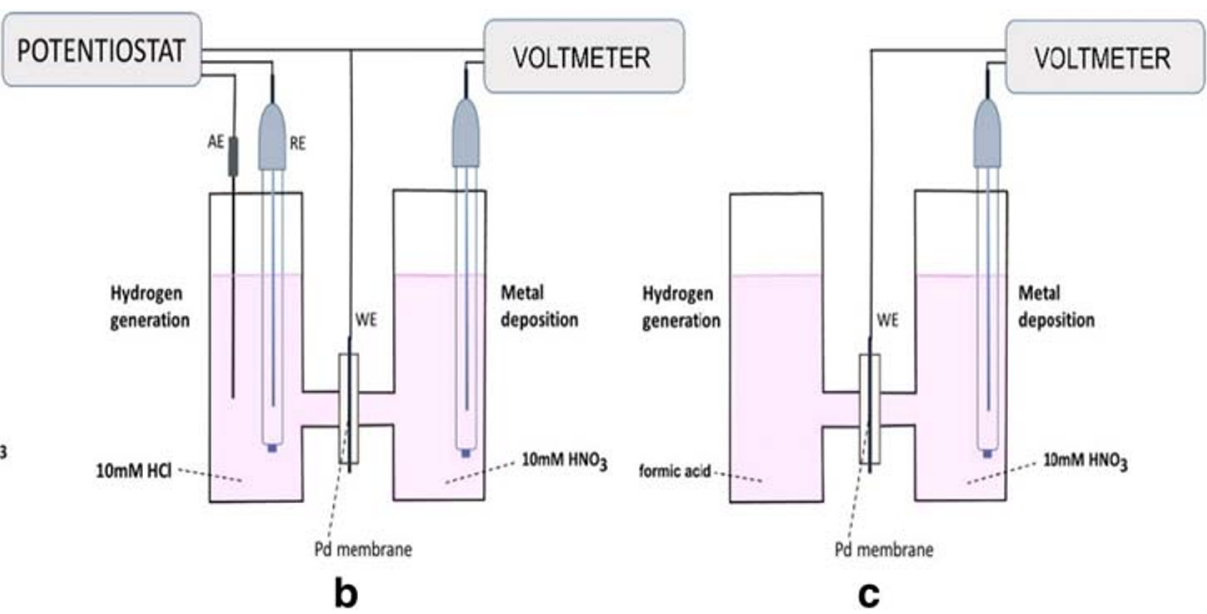

detection with a digital voltmeter on the right-hand side. In (c), the electrochemical hydrogen generation is replaced by the chemical hydrogen generation from formic acid 
In some experiments, a digital voltmeter (Fluke 114) was employed to determine the potential on the back of the palladium membrane (see Fig. 1B). The working electrode was palladium membrane $(99.95 \%, 25 \mu \mathrm{m}$ thickness, optically tested; Goodfellow Ltd., UK), the reference was a saturated calomel electrode ( $\mathrm{KCl}$, red rod; Radiometer, Denmark), and a platinum wire $0.5 \mathrm{~mm}$ diameter (Alfa Aesar, UK) served as the counter electrode. An optical microscope (GX3230, GX microscope) was used to inspect the palladium surface. Scanning electron microscopy images were obtained on a JEOL JSM6480LV or a JEOL JSM5910LV scanning electron microscope.

\section{Procedure}

The palladium membrane electrode was cut into $5 \mathrm{~mm} \times 5 \mathrm{~mm}$ pieces and contacted with conducting copper film (see Fig. 2C) before lamination into commercial polypropylene laminate (heat sealed). The plastic lamination pouch had a 2$\mathrm{mm}$ (in some cases $5 \mathrm{~mm}$ ) diameter hole punched through the center to expose the palladium membrane on both sides to electrolyte solutions. The laminated palladium membrane was mounted as membrane in a glass U-cell [29] configuration and clamped together as depicted in Fig. 1. Scanning electron microscopy (SEM) images of the bare palladium film are shown in Fig. 2A and B.

\section{Results and discussion}

\section{Indirect electrodeposition of porous silver}

Cyclic voltammetry data recorded in aqueous $10 \mathrm{mM} \mathrm{HCl}$ at the palladium membrane (see cell configuration in Fig. 1A) are shown in Fig. 3A. The reduction of $\mathrm{H}^{+}$to hydrogen gas commences at a potential of approximately $-0.2 \mathrm{~V}$ versus $\mathrm{SCE}$. The corresponding oxidation peak for hydrogen is observed at approximately $+0.2 \mathrm{~V}$ versus SCE with a potential shift indicative of ohmic losses in $10 \mathrm{mM} \mathrm{HCl}$. The hydrogen

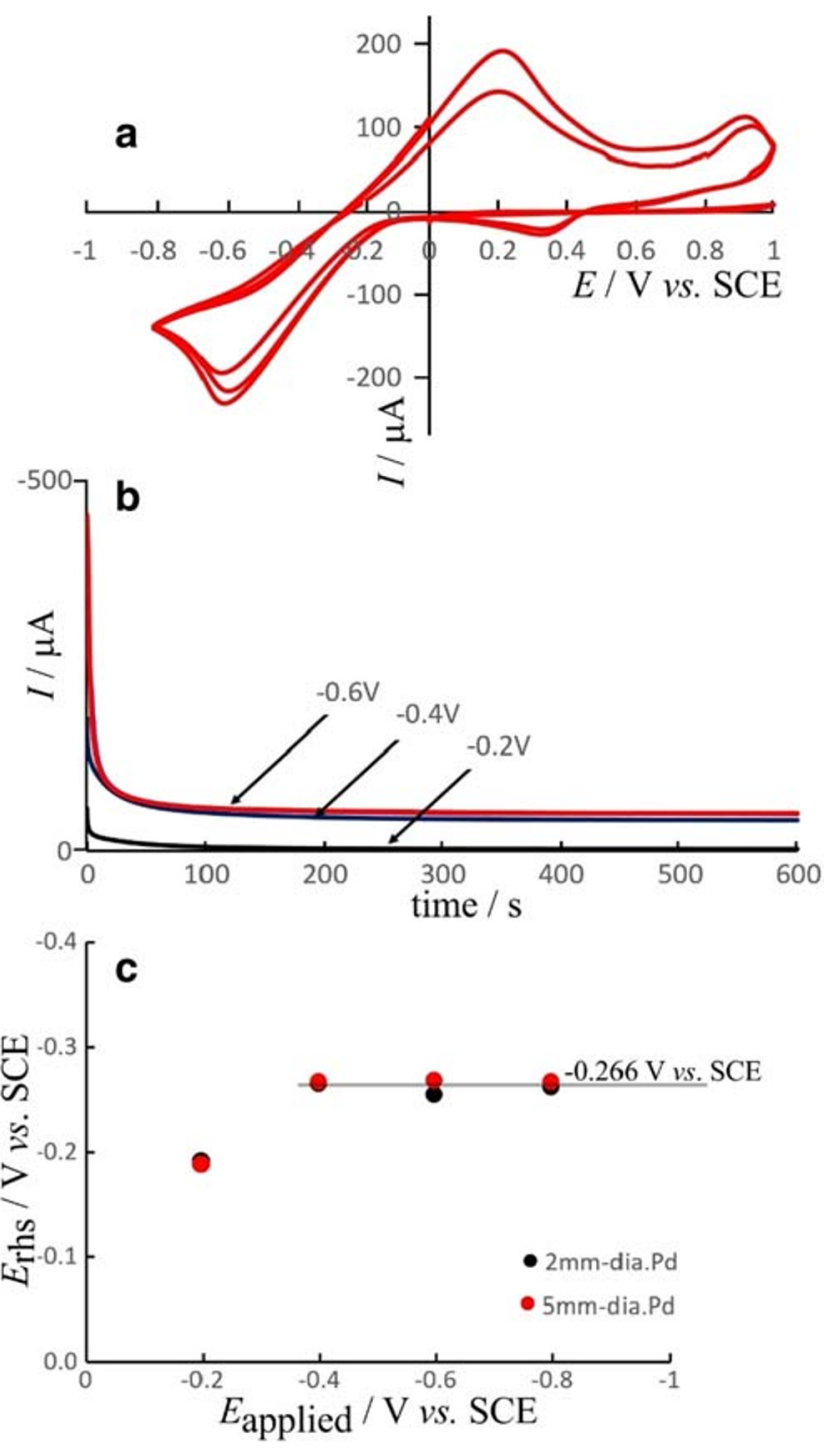

Fig. 3 a Cyclic voltammograms (scan rate $50 \mathrm{mV} \mathrm{s}^{-1}$ ) for a palladium membrane (electrochemical left-hand side $10 \mathrm{mM} \mathrm{HCl}$; right-hand side $10 \mathrm{mM} \mathrm{HNO}_{3}$ ). b Chronoamperometry data (at $-0.2 \mathrm{~V},-0.4 \mathrm{~V}$, and $-0.6 \mathrm{~V}$ vs. SCE) for hydrogen production in the electrochemistry compartment. (c) Plot of the equilibrium potential for the palladium membrane in the right-hand-side compartment as a function of applied voltage in electrochemistry compartment
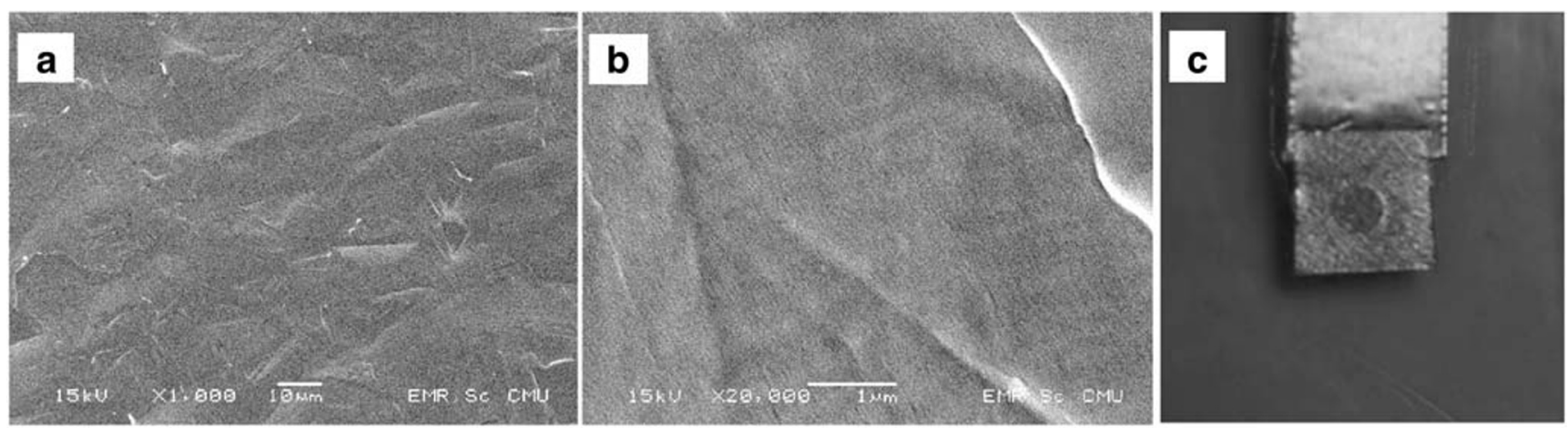

Fig. 2 Scanning electron microscopy (SEM) images at (a) lower and (b) higher magnification for the bare Pd membrane. $\mathbf{c}$ Photographic image of the palladium film with copper contact sealed into lamination foil with a 2-mm-diameter exposed central area of a $5 \mathrm{~mm} \times 5 \mathrm{~mm}$ palladium film 
evolution reaction is centered around a reversible potential of approximately $-0.20 \mathrm{~V}$ versus SCE. Two minor peaks (at +0.9 and $+0.3 \mathrm{~V}$ vs. SCE) in the more positive potential range appear after the first potential cycle and could be associated with palladium surface processes, e.g., roughening. Consistent with this idea, a corresponding change after completion of the first potential cycle also occurs in the voltammetric shape for the hydrogen response at more negative potentials.
Chronoamperometry data are shown in Fig. 3B. At constant potential (ranging from -0.2 to $-0.6 \mathrm{~V}$ vs. SCE for $10 \mathrm{~min}$ ) applied to the Pd membrane electrode immersed in $10 \mathrm{mM}$ acid (on both sides of the palladium), current transients for hydrogen evolution are observed. The magnitude of the transient current signal appears to limit at approx. $-0.4 \mathrm{~V}$ versus SCE (Fig. 3B). The potential in the second compartment containing aqueous $10 \mathrm{mM} \mathrm{HNO}_{3}$ was monitored with a voltmeter (see cell configuration in Fig. 1B). The

a
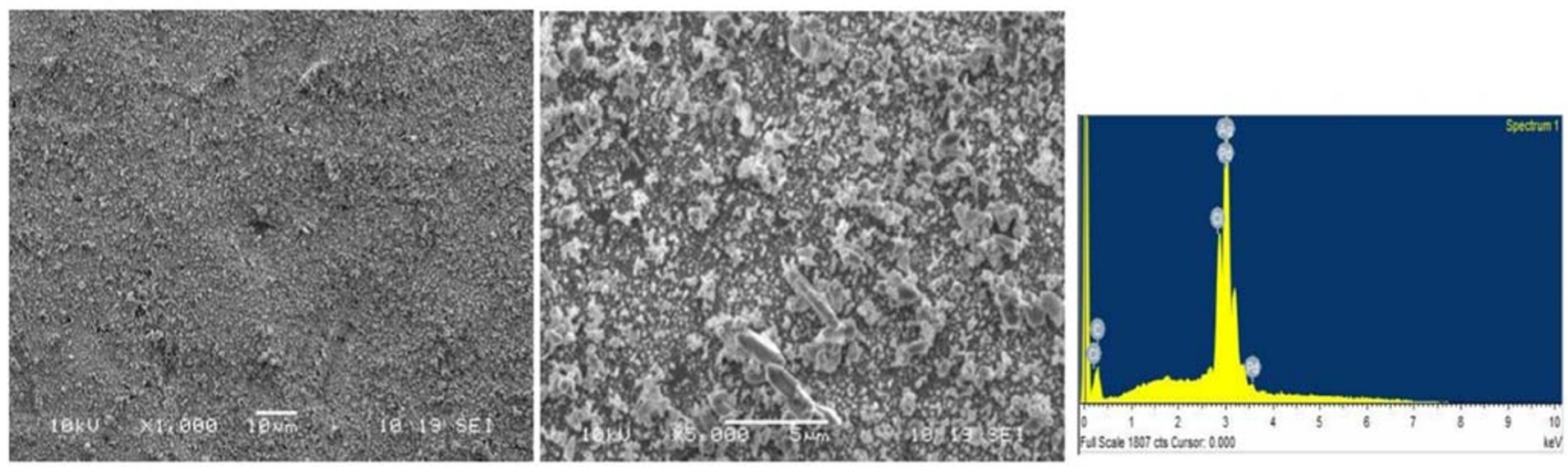

b
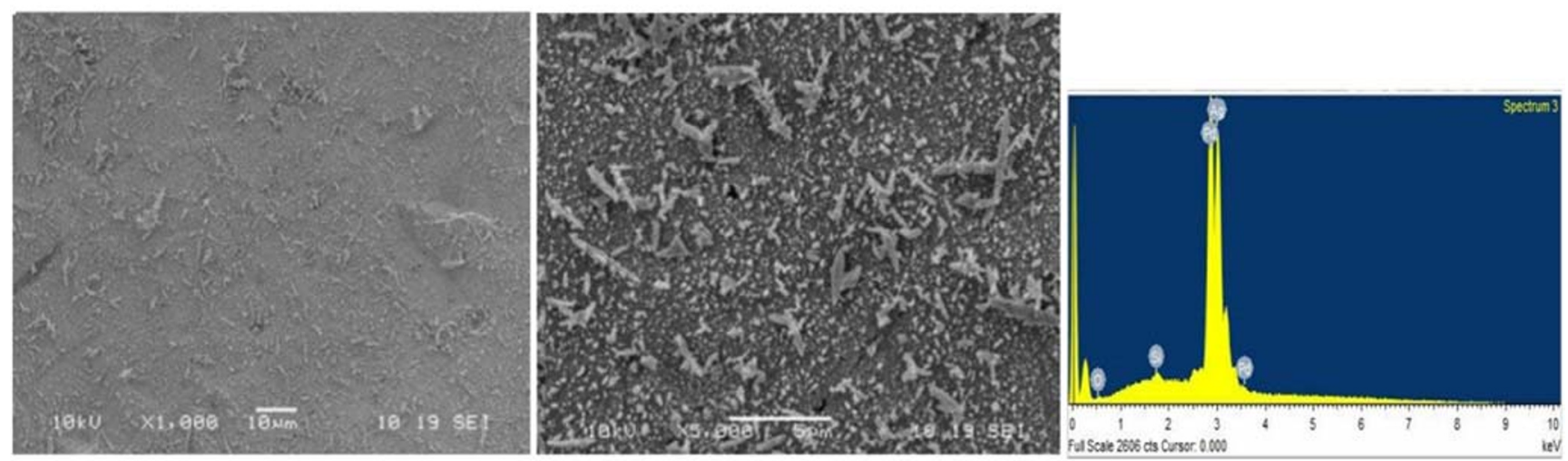

C

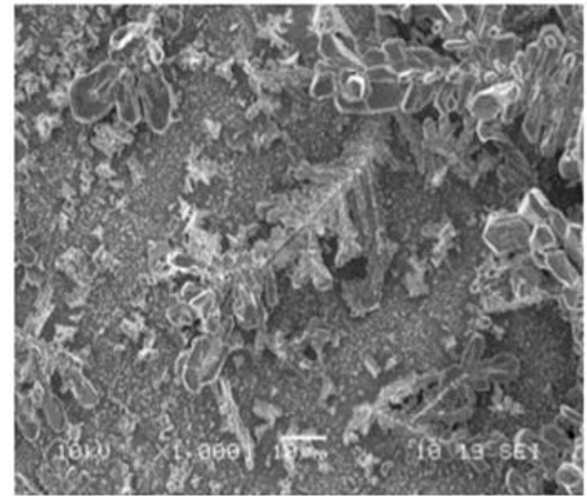

Fig. 4 SEM images and EDS analysis for (a) indirect electrodeposition of silver from $10 \mathrm{mM} \mathrm{Ag}^{+}$onto $2 \mathrm{~mm}$ diameter of Pd film at $-0.4 \mathrm{~V}$ versus $\mathrm{SCE}$ for $60 \mathrm{~min}$. (b) Indirect electrodeposition of silver from $10 \mathrm{mM} \mathrm{Ag}^{+}$
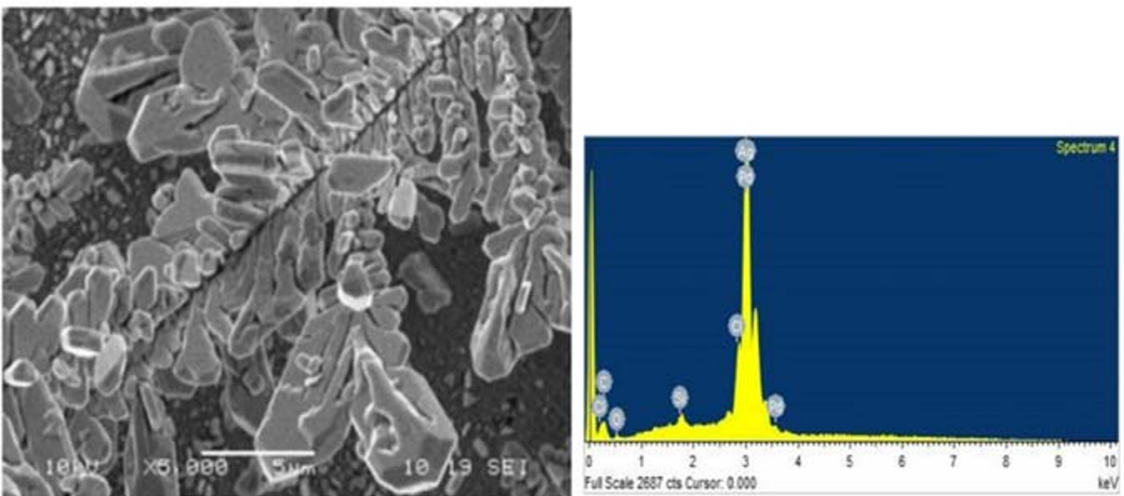

onto $2 \mathrm{~mm}$ diameter of $\mathrm{Pd}$ film at $-0.8 \mathrm{~V}$ versus SCE for $60 \mathrm{~min}$. c Indirect electrodeposition of silver from $10 \mathrm{mM} \mathrm{Ag}^{+}$onto $5 \mathrm{~mm}$ diameter of Pd film at $-0.8 \mathrm{~V}$ versus SCE for $30 \mathrm{~min}$ 
final potential at the Pd membrane in the right nonelectrochemical compartment was measured after $10 \mathrm{~min}$, and a plot of the data is shown in Fig. 3C. At sufficiently negative applied potential, hydrogen gas evolution occurred in the electrochemical compartment. Simultaneously, hydrogen gas permeated through the palladium membrane to the opposite compartment. Therefore, the potential of Pd membrane electrode (relative to SCE) on the right-hand side changed due to the change of the surface equilibrium involving $\mathrm{H}_{2}(\mathrm{~g}), \mathrm{H}_{2}(\mathrm{Pd})$, and $\mathrm{H}^{+}(\mathrm{aq})$. Constant potential readings are obtained with about 5 min equilibration time. The dominating redox process here can be written as in Eq. 1. The corresponding Nernst equation is given in Eq. 2 (based on SCE scale; using an estimated standard potential slightly positive of that for hydrogen gas evolution $E^{\circ}=0.048-0.241=-0.193 \mathrm{~V}$ vs. SCE [30]). The observed negative limit in the potential at $-0.266 \mathrm{~V}$ versus SCE (for both 2-mm- and 5-mm-diameter palladium membranes, see Fig. $3 \mathrm{C}$ ) is in reasonably good agreement with the potential expected for the limiting case of hydrogen in palladium and at approx. pH 2 (see Eq. 2). Deviation to more positive potentials could be in part due to a hydrogen activity gradient across the palladium film and non-equilibrium effects in the presence of residual oxygen in solution.

$$
\begin{aligned}
\mathrm{H}^{+}(\mathrm{aq}) & +\mathrm{e}^{-} \rightleftarrows \S \mathrm{H}_{2}(\mathrm{Pd}) \\
E_{\text {half-cell }} & =E^{\circ}+R T / F \ln \left[\mathrm{H}^{+}\right]=-0.193-0.116 \\
& =-0.309 \mathrm{~V} \text { vs.SCE }
\end{aligned}
$$

Next, two potentials at $-0.4 \mathrm{~V}$ and at $-0.8 \mathrm{~V}$ versus SCE were selected to perform an indirect electrodeposition of silver metal in the presence of aqueous $10 \mathrm{mM} \mathrm{Ag}^{+}$dissolved in $10 \mathrm{mM} \mathrm{HNO}_{3}$ on the metal deposition side (right-hand side). The total charge for 60-min hydrogen generation in the electrochemistry compartment was $1.75 \mathrm{C}$ and $4.19 \mathrm{C}$ for experiments at $-0.4 \mathrm{~V}$ and $-0.8 \mathrm{~V}$ versus SCE, respectively. More current flow at the more negative applied potential is associated with more hydrogen evolution (visible as bubbles), but the hydrogen pressure locally at the palladium surface is likely to remain constant once bubble formation is initiated. The rate of hydrogen permeation is driven mainly by the hydrogen concentration/pressure gradient and should not change significantly in this potential range.

The amount of charge used for hydrogen evolution in these experiments would theoretically correspond to a silver deposit of $6500 \mu \mathrm{m}$ or $15,600 \mu \mathrm{m}$ thickness (using a silver density of $10.49 \mathrm{~cm}^{3} \mathrm{~g}^{-1}$ ) on a circular 2-mm-diameter exposed palladium film. This is clearly unrealistic (see Fig. 4), and therefore, most of the charge for hydrogen evolution has not been used for the silver plating process. Most of the hydrogen escapes in the form of bubbles on the electrolytically active side of the membrane. Only a fraction of hydrogen passes through the palladium to effectively allow metal deposition.

The SEM-EDX data confirm the successful Ag deposition (from $10 \mathrm{mM} \mathrm{Ag}^{+}$) on the palladium membrane surface under both applied potential conditions (at $-0.4 \mathrm{~V}$ and at $-0.8 \mathrm{~V}$ vs. SCE; see Fig. 4). From SEM images in Fig. 4, the Ag particle size is seen to vary from nanometer to micrometer range distributed over the Pd surface. For these two cases, the effect of the applied potential seems insignificant with similar deposits seen for $-0.4 \mathrm{~V}$ and for $-0.8 \mathrm{~V}$ versus SCE (in first approximation, more quantitative information on the amount of silver deposits and information on any silver losses during deposition are currently not available). The deposition process is therefore likely to be initially (i) limited by hydrogen flux across the membrane and (ii) self-limited by the silver deposit partially blocking further hydrogen flux/transfer. The latter point suggests that porous metal coatings can be deposited; however, smooth non-porous coatings are not feasible.

In addition, the indirect electrodeposition of silver was also performed on the larger surface area with a 5-mm-diameter area of Pd exposed (see data in Fig. 4C). Employing constant potential at $-0.8 \mathrm{~V}$ versus $\mathrm{SCE}$ applied to the Pd membrane in

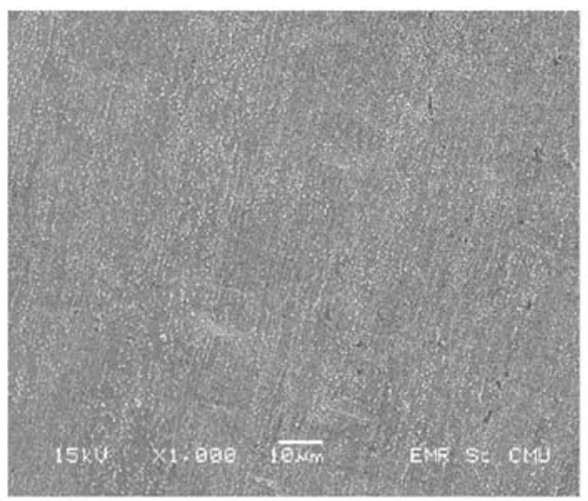

Fig. 5 Indirect silver electrodeposition using aqueous $1 \mathrm{M}$ formic acid in the left-hand-side compartment and $10 \mathrm{mM} \mathrm{Ag}^{+}$in $10 \mathrm{mM} \mathrm{HNO}_{3}$ in the right-hand-side compartment. (A, B) Electron optical images of the
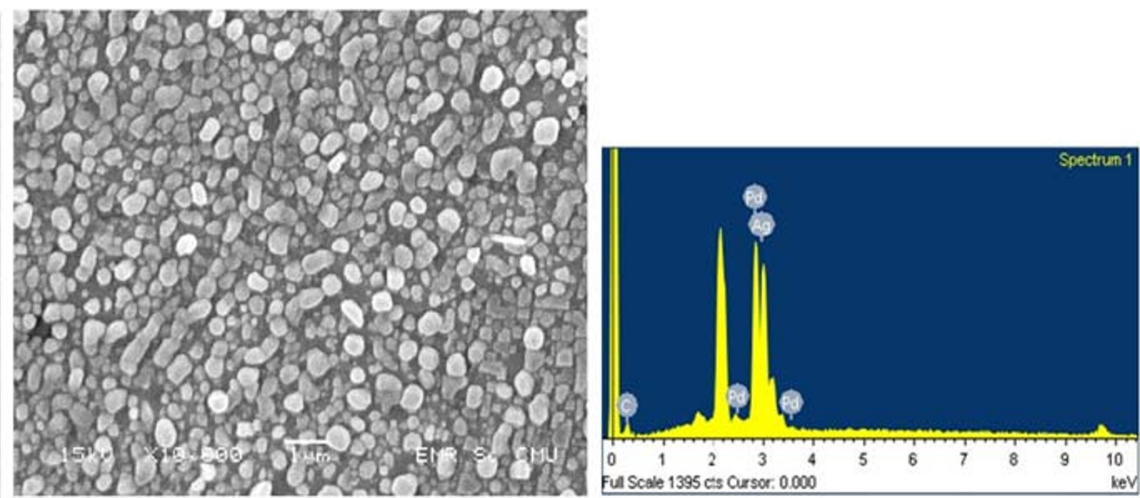

porous silver coating. (C) EDX data confirming the growth of porous silver on the palladium film (note $2.2 \mathrm{eV}$ signal due to gold coating) 
Fig. 6 Plot of the equilibrium potential for hydrogen emerging at the palladium film (see Eq. 2) versus potential. Included are standard potential values for the deposition of different types of metals. The line represents the minimum requirement for the local $\mathrm{pH}$ at the palladium surface for the metal deposition to be possible

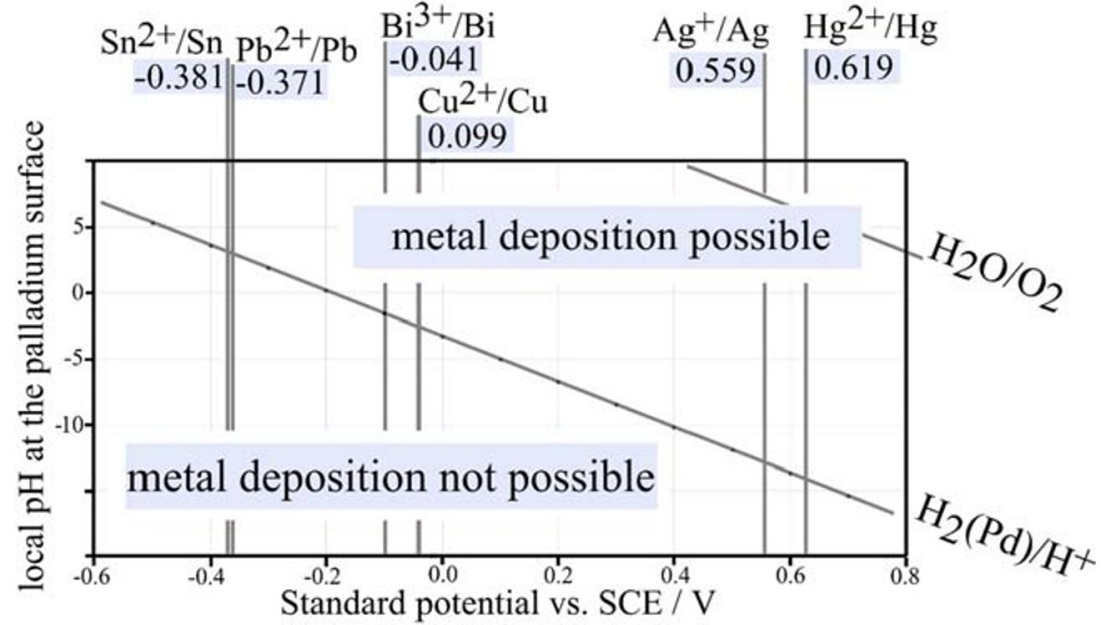

the electrochemistry compartment, the bigger surface area provided an overall higher current for the $\mathrm{H}_{2}$ production. However, the currents at the end point of the measurements remained relatively similar (for $2 \mathrm{~mm}$ diameter, $66 \mu \mathrm{A}$; for $5 \mathrm{~mm}$ diameter, $70 \mu \mathrm{A}$ ). This could be explained for example with a hydrogen bubble population at the interface limiting the rate of hydrogen generation. In spite of the similar currents for the 5-mm-diameter and 2-mm-diameter Pd membranes (that is, in spite of a lower current density), there appears to be more silver growth in the $5 \mathrm{~mm}$ diameter case (see Fig. 4C). On the 5-mm-diameter membrane, a more dendritic silver deposit can be seen. The reasons for this observation may be linked to transport conditions at the smaller/bigger electrode, but are currently unclear.

\section{Indirect silver electrodeposition driven with hydrogen from formic acid decomposition}

The proposed indirect silver electrodeposition method was also applied with the $\mathrm{H}_{2}$ generated from surface-chemical decomposition of formic acid in aqueous solution (see cell configuration in Fig. 1C) instead of the electrochemically driven hydrogen evolution (cell configuration in Fig. 1A). With the Pd membrane as catalyst, hydrogen generation and permeation through the palladium film can be spontaneous [31]. The experiment was performed as described in the "Experimental" section with the U-cell configuration, but without potentiostat (see Fig. 1C). The hydrogen generation compartment (left-hand side) was filled with aqueous $1 \mathrm{M}$ formic acid. A solution of $10 \mathrm{mM} \mathrm{Ag}^{+}$in $10 \mathrm{mM} \mathrm{HNO}_{3}$ was placed into the deposition compartment (right-hand side).

The temporal change of hydrogen concentration (hydrogen permeating through the palladium film) in the catalyst compartment causes a change in equilibrium potential of the Pd membrane in the catalyst compartment. Equilibrium potential values (measured on the right-hand side vs. SCE) rapidly drop to negative values. Typically, an equilibrium potential of $-0.17 \mathrm{~V}$ versus SCE is observed (for $1 \mathrm{M}$ formic acid in the left-hand-side compartment). This is slightly less negative compared with the equilibrium potential under conditions of

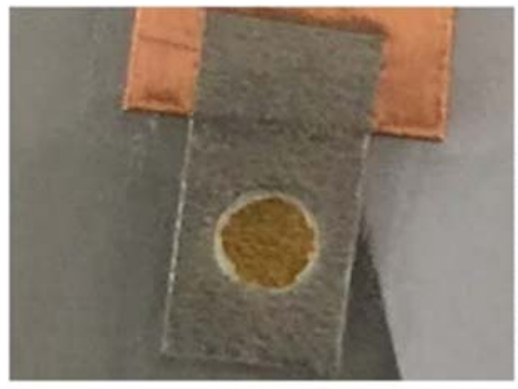

a

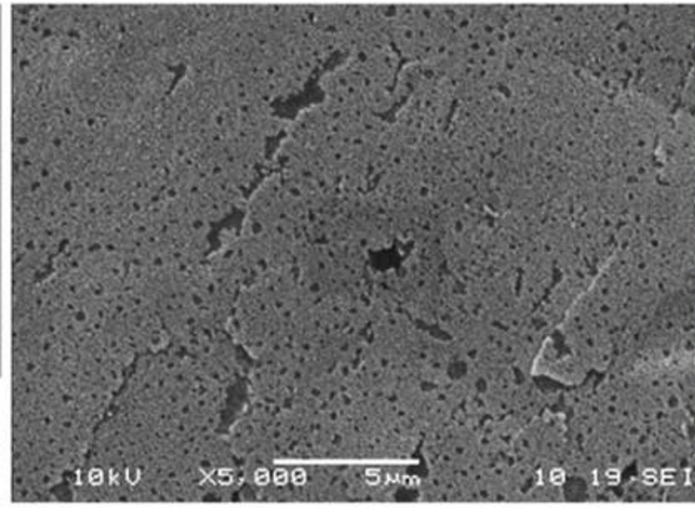

b

Fig. 7 a Optical image showing a porous gold deposit on a palladium film formed spontaneously (with or without hydrogen) after 30-min exposure to $1 \mathrm{mM} \mathrm{AuCl}_{4}^{-}$in $10 \mathrm{mM} \mathrm{HCl}$. b Electron optical image of the

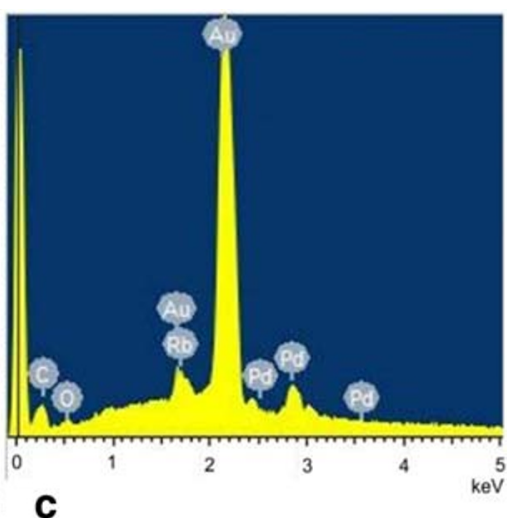

porous gold deposit. (c) EDX data confirming the formation of gold on the palladium surface 
electrochemical hydrogen generation (due to formic acid decomposition not reaching the same rate of hydrogen production, e.g. not reaching generation of 1 bar hydrogen on the lefthand side). However, the potential on the right-hand side is sufficient for metal deposition. Figure 5 shows electron optical images for silver deposits (Ag confirmed by EDX) with typically 50 to $500 \mathrm{~nm}$ grain size.

Both, electrochemically driven and chemically driven indirect metal plating processes have been demonstrated for the case of silver. The potential for hydrogen emerging from the palladium film has been linked to the driving force for the metal deposition process. Therefore, the local $\mathrm{pH}$ at the palladium surface is important for the driving force for metal deposition. In acidic (basic) conditions, hydrogen oxidation is more (less) difficult and therefore metal deposition less (more) favorable. A plot in Fig. 6 shows the line representing the minimum $\mathrm{pH}$ for a particular metal to deposit at the palladium surface. For $\mathrm{Ag}^{+} / \mathrm{Ag}$, even extremely strong acid would not stop the deposition process. However, for $\mathrm{Sn}^{2+} / \mathrm{Sn}_{\text {or }} \mathrm{Pb}^{2+} / \mathrm{Pb}$, the predicted requirement is a $\mathrm{pH}$ of 3 or higher. Therefore, depending on local $\mathrm{pH}$, this indirect metal deposition process could be applicable for a much wider range of metal systems and applications. Note that for highly oxidizing metal, also $\mathrm{H}_{2} \mathrm{O}$ can act as a reducing agent (see line for $\mathrm{H}_{2} \mathrm{O} / \mathrm{O}_{2}$ ).

\section{Direct gold electrodeposition driven by water decomposition}

It is interesting to note that very strongly oxidizing metal systems such as $\mathrm{Au}^{3+} / \mathrm{Au}$ (with a standard potential of $+1.257 \mathrm{~V}$ vs. SCE [32]) also deposit as metal film spontaneously on the palladium film, even in the absence of hydrogen. Although, the presence of chloride lowers the standard potential for $\mathrm{Au}$ (III), this still happens for $1 \mathrm{mM} \mathrm{AuCl}_{4}{ }^{-}$in $10 \mathrm{mM}$ $\mathrm{HCl}$ in contact to the palladium film. Gold metal deposition occurs with or without any hydrogen production in the lefthand-side compartment. In this case, the formation of gold is coupled to oxygen evolution from water (as has been reported for gold oxide in contact to water [33]). The plot in Fig. 6 shows the line for oxygen evolution in the right top corner. In the case of gold deposition from $\mathrm{Au}$ (III) in $10 \mathrm{mM} \mathrm{HCl}$, the presence of hydrogen is not necessary (see Fig. 7).

\section{Conclusions}

It has been shown that indirect (hydrogen-driven) electrodeposition of silver can be achieved at a palladium membrane in contact on one side to an electrolytic half cell (for electrochemical hydrogen evolution) and in contact on the opposite side to an aqueous solution containing metal cations for deposition. A 25-um-thickness palladium membrane was employed in this case for practical reasons, but thicker membranes would work in a similar way, although with a lower rate of hydrogen permeation. Replacing palladium with other materials will be an important challenge for future work.

Hydrogen generation in the electrochemical half-cell triggers hydrogen permeation through the palladium, reducing conditions on the opposite side of the membrane, and spontaneous deposition of a porous silver deposit. This approach of indirect electrodeposition driven by hydrogen could be useful when growing or recovering metals or alloys indirectly onto palladium (when direct electrodeposition is undesirable). However, at this stage, many aspects of these indirect deposition processes (e.g., effects of $\mathrm{pH}$, concentration, or type of electrolyte on both sides of the palladium membrane) remain unexplored. The effects of the palladium membrane thickness (likely to affect diffusion time and efficiency or energy losses) deserve further study.

The hydrogen generation process in the electrochemical half-cell does not have to operate at highly negative potentials. This causes energy and efficiency losses. Hydrogen generation could be performed more gently and without hydrogen bubble formation. In fact, it has been shown that this electrochemical process can be replaced completely with a simple catalytic formic acid (or biomass) decomposition process. With aqueous $1 \mathrm{M}$ formic acid, sufficient permeation of hydrogen across the palladium film occurred to cause deposition of silver in the opposite compartment. The fact that the hydrogen oxidation potential is linked to the solution $\mathrm{pH}$, allows the driving force for metal deposition to be linked to the local $\mathrm{pH}$. The higher the $\mathrm{pH}$, the more likely the spontaneous metal deposition process. For neutral solution conditions, metals such as $\mathrm{Cu}, \mathrm{Cd}$, or $\mathrm{Pb}$ should be recoverable. More work will be necessary to optimize conditions (e.g., palladium surface roughness, durability, and catalytic activity) to make processes more feasible. In the future, non-palladium hydrogen conducting films (e.g., based on graphene composites) will also provide interesting options for indirect metal deposition processes.

Acknowledgments F.M. and E.M. thank the EPSRC (EP/N013778/1). T.K. is grateful for the support from the Newton Fund: Travel Grant Researcher Link 2018 and the partial support from the Center of Excellence in Materials Science and Technology, Chiang Mai University, Thailand.

Open Access This article is licensed under a Creative Commons Attribution 4.0 International License, which permits use, sharing, adaptation, distribution and reproduction in any medium or format, as long as you give appropriate credit to the original author(s) and the source, provide a link to the Creative Commons licence, and indicate if changes were made. The images or other third party material in this article are included in the article's Creative Commons licence, unless indicated otherwise in a credit line to the material. If material is not included in the article's Creative Commons licence and your intended use is not permitted by statutory regulation or exceeds the permitted use, you will need to obtain permission directly from the copyright holder. To view a copy of this licence, visit http://creativecommons.org/licenses/by/4.0/. 


\section{References}

1. Walsh FC (2019) Trans Inst Met Finish 97(1):28-42

2. Lelevica A, Walsh FC (2019) Surf Coat Technol 369:198-220

3. Ding YJ, Zhang SE, Liu B, Zheng HD, Chang CC, Ekberg C (2019) Resour Conserv Recycl 141:284-298

4. Yang Y, Lan C, Wang Y, Zhao Z, Li B (2020) Sep Purif Technol 230:115870

5. Nsabimana A, Kitte SA, Fereja TH, Halawa MI, Zhang W, Xu G (2019) Curr Opin Electrochem 17:65-71

6. Schwarzacher W (2016) Electrochem Soc Interface 15:32-35

7. Green TA (2007) Gold Bull 40(2):105-114

8. Zhang Q, Wang Q, Zhang S, Lu X, Zhang X (2016) ChemPhysChem 17(3):335-351

9. Simka W, Puszczyk D, Nawrat G (2009) Electrochim Acta 54(23): 5307-5319

10. Yeung K, Christiansen S, Varma A (1999) J Membr Sci 159(1-2): $107-122$

11. Cheng Y, Yeung K (2001) J Membr Sci 182(1-2):195-203

12. Kitiwan M, Atong D (2010) J Mater Sci Technol 26(12):1148-1152

13. Quek X, Hamilton H (2016) Johnson Matthey Tech 60(3):190-195

14. Gallucci F, Fernandez E, Corengia P, Annaland MS (2013) Chem Eng Sci 92:40-66

15. Hamilton H (2012) Platin Met Rev 56(2):117-123

16. Rahimpour MR, Samimi F, Babapoor A, Tohidian T, Mohebi S (2017) Chem Eng Process 121:24-49

17. Gade SK, Thoen PM, Way JD (2008) J Membr Sci 316(1-2):112118

18. Al-Mufachi N, Rees N, Steinberger-Wilkens R (2015) Renew Sust Energ Rev 47:540-551

19. Pyun SI, Yoon YG (2000) Int Mater Rev 45(5):190-216
20. Flanagan TB, Oates WA (1991) Annu Rev Mater Sci 21(1):269304

21. Yang F, Taggart DK, Penner RM (2009) Nano Lett 9(5):2177-2182

22. Walkner S, Schimo G, Mardare AI, Hassel AW (2015) Phys Stat Solidi A Appl Mater Sci 212:1273-1280

23. Tong XQ, Sakamoto Y, Lewis FA, Bucur RV, Kandasamy K (1997) Int J Hydrog Energy 22(2-3):141-144

24. Luidold S, Antrekowitsch H (2007) JOM J Min Met Mater Soc 59(6):20-26

25. Adams BD, Chen A (2011) Mater Today 14:283-289

26. Chen YP, Bashir S, Liu JL (eds) (2019) Nanostructured materials for next-generation energy storage and conversion. Springer, Berlin

27. Sherbo RS, Delima RS, Chiykowski VA, MacLeod BP, Berlinguette CP (2018) Nature Catal 1(7):501-507

28. Sherbo RS, Kurimoto A, Brown CM, Berlinguette CP (2019) J Amer Chem Soc 141(19):7815-7821

29. Brown R, Madrid E, Castaing R, Stone JM, Squires AM, Edler KJ, Takashina K, Marken F (2017) ChemElectroChem 4(5):1172-1180

30. Pourbaix M (1974) Atlas of electrochemical equilibria in aqueous solutions. National Association of Corrosion Engineers, p 359

31. Mahajan A, Bhattacharya SK, Rochat S, Burrows AD, Fletcher PJ, Rong YY, Dalton AB, McKeown NB, Marken F (2019) ChemElectroChem 6(16):4307-4317

32. Pourbaix M (1974) Atlas of electrochemical equilibria in aqueous solutions. National Association of Corrosion Engineers, p 401

33. Diaz-Morales O, Calle-Vallejo F, de Munck C, Koper MTM (2013) Chem Sci 4(6):2334-2343

Publisher's note Springer Nature remains neutral with regard to jurisdictional claims in published maps and institutional affiliations. 